\section{IMPROVED TECHNTC FOR BLOOD-COUNTS: RAPID METHOD FOR SECURING EXACT AMOUNT OF SUSPENSION}

Alran Fustis, B.S., Pir.B., M.D., New Orleans Assistant I'rofessol of Dietetles and Nutrition, Medical Department of the Tulane Unlversity of Louisiann

Many clinicians regard total white or red counts as an arduous and lenrthy procedure. After noticing that most of their time has been consumed in trying to drop the exact amount of suspension on the counting-chamber, I feel justified in calling attention to the technic which I have found for many years both rapid and exact. It may be original or I may have observed some one else doing the same thing, but so far as $I$ know it is original, and none of the text-books on laboratory technic covers the point in question, being content

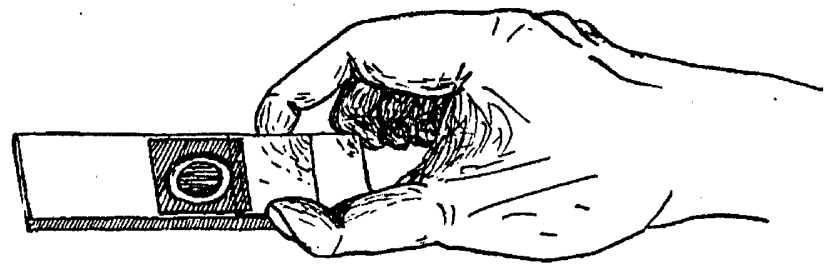

Flg. 1.-Manner of holding cover-glass.

to say: "A small drop of the solution (?) is carefully placed on the center of the counting-chamber, that is, over the ruled scale. The cover-glass is immediately adjusted before the corjuscles can sink, and pressed down at the margin until Newton's rings appear. If these do not remain after removal of the pressure, the preparation must be made over again."

I have observed some clinicians make as many as five or six preparations before obtaining satisfactory results, which can be readily obviated in a single preparation by adhering to the following technic:

After the usual shaking of the pipet, and expulsion of a few drops of the suspension, a good sized drop is placed on the counting-chamber, no particular attention being paid to its size. The cover-glass, which has been previously cleaned, is then rapidly grasped between the thumb and index-finger of the right hand ( $\mathrm{Fig} .1$ and Fig. $2 A$ ), while the slide is steadied on the table with the left hand. While firm pressure
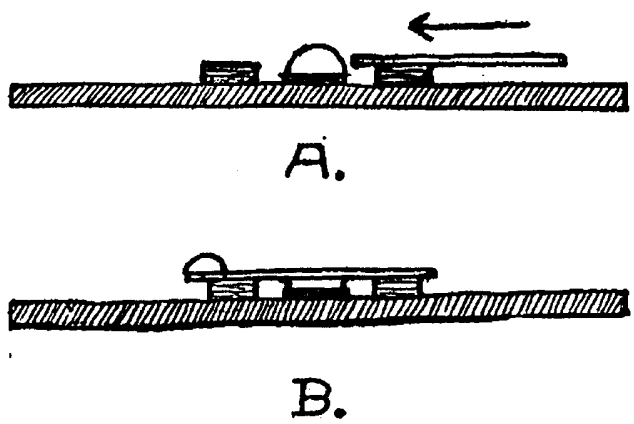

Fig. 2-ITorizontal view of counting-chamber, drop of suspenston And coverglass; $A$, before sliding cover-glass through drop. $B$, after sliding cover-glass tlarough drop.

is exerted on the cover-glass it is rapidly slid across the counting-chamber, through the drop of suspension on it. The cover-glass will cut through the drop at exactly $0.1 \mathrm{~mm}$. The excess from the drop will rise on top of the cover-glass and jump across the moat (Fig. 2B). Newton's rings will be obtained in each instance. The drop on top of the edge of the cover-glass is wiped or soaked up with the point of a towel or blotting-paper and the preparation is completed.

Precautions to be observed are:

1. Clean cover-glass.

2. lerfectly dry moat.

3. Rapid and perfectly horizontal motion of the cover-glass. 108 Baronne Street.

\section{Therapeutics}

\section{PUERPIRAL INFECTION}

(Concluded from page 1901)

\section{TREATMLNT OF PUERTERAL INFECTION}

If some form of puerperal infection has occurred, of course the first decision is as to whether or not it is local or general. In a local or pelvic disturlsance with more or less rise of temperature but without any symp. toms of general infection, the treatment should be conservative and more or less symptomatic. 'The bowels should be earefully attended to, the dict should be simple but sufficient, large amounts of water should be drunk to dilute all the secretions, and Fowler's position should be used more or less continuously to encourage drainage. Again, vaginal douches generally should not be given.

It has been shown that the action of yeast increases leukocytosis and more or less inhibits intestinal intoxication; therefore its administration is good trearment in most infections and is very valuable in pelvic infections. From one-sixth to one-fourth of an ordinary compressed yeast-cake, dissolved in a glass of water, should be given three times a day, unless it causes too much looseness of the bowels. Vaginal donches of yeast solutions have been used and are said to be of value.

Of course the vaginal discharge, or, better, the uterine secretion directly obtained, should be studied bacteriologically to decide, if possible, what infection is present. According to Watkins, ${ }^{1}$ the bacteriologic examination of vaginal and uterine secretions is of relatively small value, as the results are often uncertain and misleading. Blood-cultures are the only means at present of accurate diagnosis of the variety of infection. The resujt of this examination may suggest the use of an antiserurn or a vaccine, if either be deemed advisable. The blood sliould also be examined for pathogenic bacteria.

If a parturient patient has a sudden chill more or less severe, with a rapid rise of temperature which persists in some degree and is not intermittent, and a rapid pulse, puerperal infection has probably developed, unless some serious condition like pneumonia is abont to occur. Other symptoms of this general streptococcic infection are: a diminished amount of lochial discharge, perhaps even without odor; more or less tenderness in the pelvic region; a coated and perhaps dry tongue; bad, perhaps septic, breath; scanty urine; severe lumbar pains ; tympanites; at times yellowing of the skin, and later, if the infection progresses and becomes serious, possibly delirium. 'The progress of the fever is that of a typical septicemia. There may be irregular chills, profuse sweatings and more or less leukocytosis. If the lungs, breasts, kidneys and throat have been excluded as the location of the cause of the temperature rise and onset of symptoms, and if the uterus is tender and enlarged, as it generally is, acute puerperal streptococci infection is in evidence.

The insistence here should be on the fact that because there is a septic puerperal infection, it is not forthwith an indication for a uterine curettage, or intrauterine or vaginal douching or any other severe operation. The general treatment just outlined for a more localized simple puerperal pelvic infection should be carried out, with more or less tepid spongings to control the high tempera-

1. Wrtkins, T. J. : Puerperal Infection, Am. Jour. Obst. and Dis. Women and Chtld., September, 1013 ; abstr., Tire JounNaL A. M. A., Oct. 18, 1913, p. 1485 . 